\title{
Expecting to Work, Fearing Homelessness: The Possible Selves of Low-Income Mothers ${ }^{1}$
}

\author{
SHAWNA J. LEE ${ }^{2}$ \\ School of Social Work and Merrill-Palmer \\ Skillman Institute for Child \& Family \\ Development
}

Wayne State University

\author{
DAPHNA OYSERMAN \\ Department of Psychology and \\ School of Social Work \\ University of Michigan
}

\begin{abstract}
We explored the content of possible selves of low-income mothers and the strategies they have to work on their possible selves. Positive expected possible selves focus on getting a job, making ends meet, and caregiving. Negative to-be-avoided possible selves focus on failing to make ends meet, losing (or not getting) jobs, and problems with mental health. Immediate social context - rather than demographic characteristics or global work-family variables - was associated with content of possible selves. Controlling for demographic and work-family variables, job-focused possible selves (and strategies to attain them) were more salient; and caregiving and mental-health-related possible selves were less salient to mothers in job-training programs vs. welfare offices.
\end{abstract}

Possible selves are the future-oriented aspect of self-concept; that is, the positive and negative selves one fully believes and expects to become or wants to avoid becoming (Markus \& Nurius, 1986). By providing concrete positive expected and negative to-be-avoided future images, possible selves personalize goals and connect current behaviors to future states. In this way, possible selves improve self-regulatory capacity (Cross \& Markus, 1994; Oyserman \& Markus, 1990; Oyserman, Terry, \& Bybee, 2002) and make one's current situation seem meaningful (Cross \& Markus, 1991). Self-denial, self-sacrifice, and continued effort in the face of long odds make sense in the present only when linked to belief in future attainment of self-relevant goals. Possible selves can represent competing future selves, such as imagining the competing demands of breadwinning and caregiving.

${ }^{1}$ The first author was supported by NIMH Training Grant T32-MH63057 (Michigan Prevention Research Training Grant; D. Oyserman, PI) during preparation of this manuscript. An earlier version of the paper was presented at a symposium at the 2005 annual meeting of the American Psychological Society, Los Angeles, CA.

${ }^{2}$ Correspondence concerning this article should be addressed to Shawna J. Lee, School of Social Work, 4756 Cass Avenue, Detroit, MI 48201. E-mail: shawnal@wayne.edu or to Daphna Oyserman, Wayne State University, Department of Psychology and School of Social Work, University of Michigan, Research Center for Group Dynamics, 5240 Institute for Social Research, 426 Thompson Street, Ann Arbor, MI 48106-1248. E-mail: daphna@umich.edu 
Possible selves reflect developmentally and contextually salient tasks and challenges (Oyserman \& Markus, 1990; Oyserman \& Fryberg, 2006; Oyserman et al., 2002). For example, occupational and interpersonal possible selves (e.g., getting married) are salient among middle-class individuals in early adulthood, and family and parenting possible selves become more salient with age (Cross \& Markus, 1991; Hooker, Fiese, Jenkins, Morfei, \& Schwagler, 1996; Strauss \& Goldberg, 1999). Job-focused possible selves become less salient (Cross \& Markus, 1991) and physical health-related possible selves become more salient (Frazier, Hooker, Johnson, \& Kaus, 2000; Hooker \& Kaus, 1994) among middle-class respondents in later adulthood.

Possible selves are also thought to be influenced by social context. There is relatively little research on how social contexts may shape possible selves. For example, while a review of qualitative research has indicated that poverty may limit the possible selves that teens see as relevant and attainable (Oyserman \& Fryberg, 2006), quantitative analyses have suggested that the impact of poverty as a social context is less on content of possible selves and more on availability of strategies to work on attaining possible self-goals (Oyserman, Johnson, \& James, 2009).

We did not find research examining possible selves of low-income mothers. We begin to address this gap in the current study by asking to what extent breadwinning and caregiving are salient possible selves and to what extent these possible selves are linked with current behavioral strategies among women transitioning from welfare to work.

Understanding the possible selves of low-income mothers is especially important following the change in welfare law in 1996. Previously, lowincome mothers were entitled to welfare benefits as long as they had children in their care. Caregiving, rather than breadwinning, was assumed to be a central task of mothers, and the 1996 welfare reform law is evidence that this assumption no longer holds true. Welfare benefits are strictly time-limited (typically to a lifetime total of 5 years), and mothers are required to leave home to participate in job search and job-training programs in order to receive even these time-limited benefits. The breadwinning role of mothers has been centralized, and even women caring for infants and young children are under considerable pressure to provide for their families through paid employment (Blank, 2002; Haskins \& Offner, 2003).

While prior ethnographic studies have suggested that low-income mothers believe that breadwinning is integral to parenting, it is also clear that working outside the home and caregiving do not easily blend, particularly for single parents (Danziger \& Lin, 2000; DeParle, 2004; Edin \& Kefelas, 2005; Hays, 2003; Morris \& Coley, 2004; Scott, Edin, London, \& Mazelis, 2001; Shipler, 2004). Finding childcare and reliable transportation 
are among the significant obstacles low-income mothers face when trying to find and maintain employment (Danziger, Ananat, \& Browning, 2004; Danziger et al., 2000; Jackson, 1997; Lee \& Vinokur, 2007). Worry about the availability and quality of childcare is associated with increased maternal strain and depression (Jackson, 1997; Lee \& Vinokur, 2007). Juggling the demands of caregiving and breadwinning requires effort, perseverance, and creativity (Roy, Tubbs, \& Burton, 2004), as well as a sense of competency in one's ability to handle such tasks (Jackson \& Scheines, 2005). When breadwinning possible selves are salient, low-income women may be better equipped to persevere at job search and job maintenance in the face of these difficulties, because possible selves help to sustain goal-directed motivation and self-regulation.

\section{Possible Selves as Motivational Resources}

Studies suggest that by itself, imagining a future self-goal is unlikely to be sufficient to sustain effort over time. For possible selves to impact outcomes, they must be cued in relevant contexts, linked to strategies, and balanced; that is, they must include both positive selves to work toward, and feared selves to strive away from (Oyserman, Bybee, \& Terry, 2006; Vinokur \& Schul, 1997). Balanced possible selves highlight the need for strategies focused on simultaneously moving toward positive expected possible selves and away from negative feared possible selves, and for strategies focused on perseverance in the face of barriers (Oyserman, Bybee, Terry, \& Hart-Johnson, 2004).

For low-income women, having balanced possible selves and strategies to attain expected possible selves and to reduce chances of becoming like one's to-be-avoided job-focused, caregiving, and breadwinning possible selves may be especially important, given that obstacles to attaining employment and making ends meet are common and well documented (Danziger et al., 2000; Lee \& Vinokur, 2007). Yet, past research focused on caregiving and employment possible selves has focused on middle-class adults (Hooker et al., 1996; Morfei, Hooker, Fiese, \& Cordeiro, 2001), with little attention given to the intersection of work and family among lowincome women. We move beyond prior work by examining the possible selves and strategies of low-income women, asking whether these possible selves reflect central life tasks, and if chronic (e.g., race, education) and temporary (e.g., being in job training) contexts influence content of possible selves and strategies, and whether they are associated with perceived level of work-family conflict and perceived efficacy to handle work-family conflict. 
We expect that caregiving and breadwinning possible selves will be central to low-income women, much as they are in middle-class contexts, but that making ends meet will also be a focus of possible selves for low-income women. In the current study, we examine both the salience of these possible selves and the likelihood of having strategies to work toward them. We investigate how relevant demographic variables that shape chronic social context (i.e., age, education, race, number of children, presence of young children, current work status) influence the content of possible selves; and how possible selves and strategies of possible selves relate to measures of perceived work-family conflict and perceived efficacy to handle work-family conflict. With regard to immediate social context effects, we expect that job-focused possible selves will be particularly salient for low-income women in job-training programs who are under considerable immediate pressure to find employment. As an initial test of these hypotheses, we sampled mothers in both welfare offices and in job-training programs.

\section{Method}

\section{Participants and Procedure}

Women $(N=327)$ were recruited from Department of Human Services (DHS) locations in Michigan: one welfare office waiting room $(n=137)$, and two job-training programs $(n=190)$. Mothers recruited from job-training programs were participating in the program to meet DHS welfare-to-work requirements, and sessions were held in a location separate from the welfare office. Welfare applicants were applying for benefits or visiting a caseworker. Although according to policy mandates most welfare recipients would eventually be required to participate in some form of job training, at the time of data collection they were not currently in a job training context. The jobtraining sites were in more urban areas, and differed in some demographic characteristics, as discussed in the Results section and as summarized in Table 1.

All participants in these programs were asked to voluntarily complete a short, anonymous survey on work and family issues. They were given instructions on completing the survey, thanked, and reimbursed with a small cash gift of $\$ 10$. Because women received a small cash gift for participating in the study, a requirement of the recruitment locations and the university Institutional Review Board was that all women be provided the opportunity to participate in the survey. Thus, respondents were not prescreened with regard to their suitability for our study. Screening of respondents occurred later, based on responses to demographic questions. 
Table 1

Sample Descriptive Statistics by Study Location

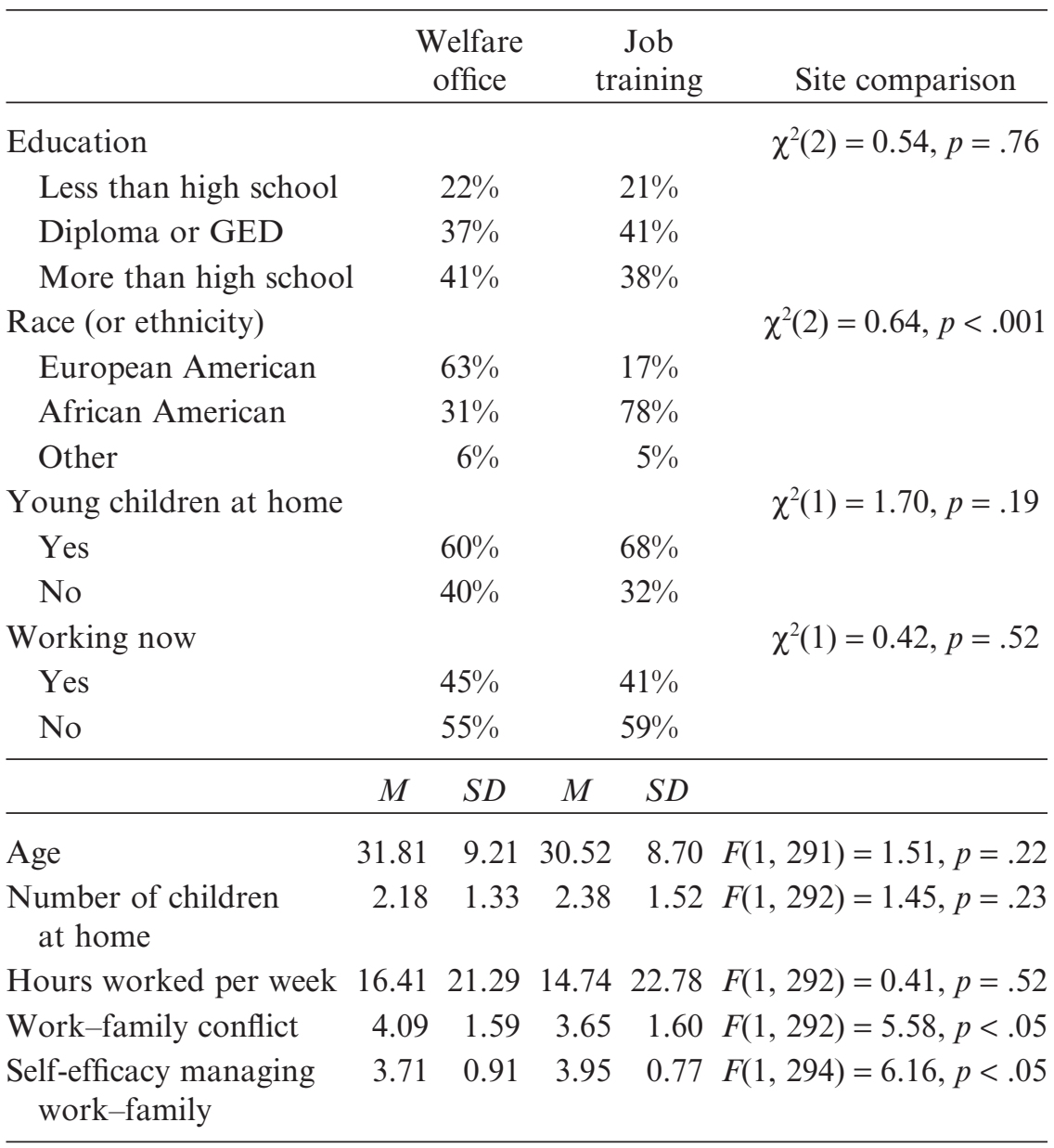

Note. Young children at home: $0=$ no children under age $5 ; 1=$ at least one child under age 5 at home. Working now (currently working for pay): $0=N o ; 1=$ Yes. Work-family conflict: $1=$ never to 7 =always. Self-efficacy managing work-family: $1=$ not at all confident to $5=$ very confident .

It was necessary to drop 14 women who did not currently have children living at home, as well as 16 women who failed to answer key demographic questions (i.e., age, education, whether they were currently working, whether they had children at home), resulting in a final sample of 298 mothers with 
children living at home who completed the majority of the survey instrument (DHS welfare office, $n=125$; job-training sites, $n=173$ ). An additional 23 respondents who did not complete the possible self measure were omitted from analyses involving possible selves variables. Missing data on the possible self measure did not differ significantly according to recruitment site, with a noncompletion rate of $6 \%$ at the DHS welfare office $(n=8)$ and $9 \%$ at the job-training site $(n=15)$.

The majority $(65 \%)$ of mothers in the final sample were caring for young children under the age of 5 years. Mothers were aged 18 to 59 years $(M=31.1$ years, $S D=8.9$ ). Mothers' racial/ethnic status was African American $(n=160 ; 57.8 \%)$; European American $(n=103 ; 37.2 \%)$; or Hispanic, biracial, or members of another race/ethnic group $(n=14 ; 5.1 \%)$. Educational levels varied: $21 \%$ of mothers reported less than high school, $39 \%$ of mothers reported graduating from high school (with a high school diploma or GED), and $40 \%$ of mothers reported some education beyond high school. Approximately $42 \%$ of respondents were working at least part-time for pay at the time they completed the questionnaire.

\section{Measures}

Site

Site was coded as 0 if the mother was recruited from a welfare office. It was coded as 1 if the mother was recruited from a job-training program.

\section{Demographics}

Participants responded to several demographic questions. They provided information on their age; education $(1=$ less than high school; $2=G E D$ or high school diploma; 3 = some education beyond high school); number of children at home; presence of young children at home $(0=$ no children under age $5 ; 1=$ at least one child under age 5); race $(1=$ White; $2=$ African American; $3=$ Hispanic, biracial, or other racelethnic group); whether they were currently working $(0=N o ; 1=Y e s)$; and if working, hours worked per week.

\section{Work and Family}

Work-family conflict (WFC). WFC (Bohen \& Viveros-Long, 1981) was measured using two statements that were rated on a 7-point scale ranging from 1 (never) to 7 (always; $M=3.84, S D=1.59, \alpha=.74$ ). Participants 
provided their responses to the statements "Balancing work and family feels impossible," and "I feel torn between my work and my family."

Self-efficacy managing work-family. In the pilot phase of this study, the authors developed a six-item measure. The items were rated on a 5-point scale ranging from 1 (not at all confident) to 5 (very confident; $M=3.81$, $S D=0.84, \alpha=.86$ ). Following a stem ("How confident do you feel about doing the following things successfully ...?"), the items are "keep track of the housework and manage employment"; "get my children to day care or school and get myself to work"; "keep my employer and my spouse or partner happy"; "keep up with the bills and have enough time with my children"; "keep a job and manage family demands"; and "get my child to the doctor or school activities and stay at work when needed."

\section{Possible Selves}

Possible selves for the coming year were assessed with an open-ended measure that had two stems ("Next year, I expect to be ...,", and "Next year I want to avoid being ..."), with each prompt followed by four blank lines for respondents to write in their possible selves. After they wrote in their possible selves, respondents were asked if they were doing anything to work toward expected possible selves or to make to-be-avoided possible selves less likely.

The open-ended measure was content-coded using a system based on research with low-income minority adolescents (Oyserman \& Markus, 1990; Oyserman et al., 2002, 2004). Categories were modified to be appropriate for adult women and were content-coded for the following areas: making ends meet (material concerns), jobs, education, caregiving, mental health, and physical health possible selves. Fewer than $10 \%$ of the study respondents generated physical health possible selves, so this category was dropped from analysis. Examples of responses in each domain follow.

Content coding was conducted by two undergraduate research assistants who were blind to the study hypotheses. Interrater agreement, obtained by coding the 178 possible selves generated by 30 participants, was $87.6 \%$ ( 22 responses were not identically coded). All remaining responses were doublecoded, with disagreements discussed to agreement. Given skewed distribution, expected and to-be-avoided possible selves and strategies in each domain were recoded as 0 if the respondent had not generated a response that could be coded in that domain, and as 1 if the respondent had generated at least one response that could be coded in that domain.

Job-focused. Expected possible selves coded as jobs described a general expectation of being steadily employed (e.g., "working more," "working somewhere stable," "have a stable job," "have a lifetime job"), specific jobs (e.g., "opening a day care," "accounting," "medical billing," "emergency 
medical technician," "certified medical assistant," "day care," "home health care aid," "mortgage broker," "real estate"), and perhaps optimistic expectations that the job would be enjoyable or more career-oriented (e.g., "working in a job I love," "making a career," "career oriented and working toward bigger and better things"). To-be-avoided job-focused possible selves included a general desire to avoid unemployment (e.g., "being unemployed," "struggling with a job," "not working").

Caregiving. Expected caregiving possible selves described caring for children and family (e.g., "spending more time with my family," "be an excellent mom," "be a more patient person and mother"), and parenting as a means of helping one's children achieve more (e.g., "help my son's reading level improve"). To-be-avoided possible selves described general concerns about fulfilling important responsibilities of parenting (e.g., avoid "being a bad mother," "I will not raise my family in the ghetto"), work-family concerns (e.g., avoid "my kids crying that they want me home," "time away from my children"), and concerns about interactions with significant others (e.g., avoid "drama between me and my daughter's dad," "avoid 'childish' men," "being in a dead-end relationship," "unhealthy relationships with men and peers").

Education-focused. Expected possible selves coded as education-focused described ongoing and future plans (e.g., "taking a Spanish class," "be in a school for computers," "in school for medical billing," "get better grades," "taking classes to further my work"). To-be-avoided possible selves often focused on avoiding failure (e.g., "not passing my classes," "missing class").

Making ends meet. Expected possible selves coded as making ends meet (or meeting material needs) related to concerns with basic necessities (e.g., "having reliable transportation"), improving on one's material situation (e.g., "renting a better apartment," "purchasing a home," "having my own apartment," "getting a new car"), and meeting financial goals (e.g., "get credit counseling and consolidate student loans," "pay off debt"), including financial goals directly tied to children (e.g., "I plan on having a savings bond for my daughter," "I want better things for me and my child," "have me and my family in our own place"). To-be-avoided possible selves coded as making ends meet described worry about debt and failure to attain basic necessities (e.g., avoid "being homeless," "money problems," "getting behind on my bills," "struggling with shut-off notices"), as well as not wanting government assistance (e.g., avoid "being on state funded aid," "being at Work First," "cash and food assistance from the government"). In terms of strategies, respondents mentioned specific behaviors that would help them maintain work and stay off welfare (e.g., avoiding "missing days of work," "being late for work," "conflict at work").

Mental health. Expected and to-be-avoided possible selves coded as mental health focused on handling stress (e.g., avoid "procrastination," 
"being so stressed out," "making very bad decisions"), depression (e.g., avoid "feeling depression," "falling deeper into depression," "living in quiet desperation"), and affective response to life (e.g., avoid "taking everything personal," "being mean," "fighting," "feeling unneeded," "being an angry and unhappy person").

Possible self strategies. Within each category of possible selves, strategies were coded by noting whether at least one strategy was generated for each category of possible selves. For example, breadwinning strategies were general (e.g., "looking for a job," "going on interviews and filling out applications") and specific (e.g., "every day I go to at least one place and fill out an application, even if I have already applied," "looking for employment, even though I already have a job"). Strategies to make ends meet include "staying in transitional housing to save money." Education strategies focused on a few issues (e.g., "applying for college courses," "studying every day"). Mental health strategies often referenced avoiding negative social contacts (e.g., "staying away from people who are negative," "staying to myself").

Balance in possible selves. Balance was coded by counting the pairs of expected and to-be-avoided possible selves in the same domain. For example, a mother who said she expected to be a "homemaker" and wanted to avoid "leaving my children" would be coded as having a balanced caregiving possible self, as would a mother who said she expected to "be a better parent to my kids" and wanted to avoid "trouble with my daughter." A mother who expected to "have a better job" or "be working full time" and wanted to avoid "not having a job" would be coded as having a balanced breadwinning possible self.

\section{Results}

\section{Analysis Plan}

First, we present Pearson correlation analyses (Bonferroni adjusted for the large number of variables included) examining demographic and workfamily variables and sample descriptive statistics (Table 1) and describe the content of women's possible selves (Table 2). Then, we present regression results that demonstrate that the possible self and strategy variables are not systematically associated with the demographic or work-family variables, but are associated with immediate context, even when controlling for demographic and work-family variables.

Because it was not possible to assign participants to site randomly, we examined the possibility that site was associated with our demographic and work-family controls using ANOVAs with Bonferroni post hoc contrasts (or 
Table 2

Content of Possible Selves

\begin{tabular}{lcccc}
\hline & \multicolumn{4}{c}{ Women with one or more (\%) } \\
\cline { 2 - 5 } PS domain & $\begin{array}{c}\text { Expected } \\
\text { PS }\end{array}$ & $\begin{array}{c}\text { To-be- } \\
\text { avoided PS }\end{array}$ & $\begin{array}{c}\text { Strategies for } \\
\text { expected or } \\
\text { to-be-avoided PS }\end{array}$ & $\begin{array}{c}\text { Balanced } \\
\text { pair of PS }\end{array}$ \\
\hline Job-focused & 74 & 36 & 73 & 29 \\
Making ends meet & 62 & 44 & 65 & 23 \\
Education & 40 & 10 & 34 & 7 \\
Caregiving & 34 & 17 & 31 & 7 \\
Mental health & 15 & 28 & 29 & 7 \\
\hline
\end{tabular}

Note. $\mathrm{PS}=$ possible selves.

chi-square tests when appropriate; see Table 1). We then examined the influence of immediately salient social context $(0=$ welfare office; $1=$ job-training program) on likelihood of having at least one (expected, to-be-avoided, and balanced pairs) possible self and at least one strategy in each domain using a series of logistic regressions that controlled for age, education, number of children at home, presence of young children at home, race, whether respondent was currently working, and hours worked per week. Results of these analyses are summarized in Table 3, with significant results described later.

\section{Content of Possible Selves}

\section{Expected Possible Selves}

Almost three quarters (74\%) of mothers generated at least one expected possible self that focused on jobs (breadwinning), and $62 \%$ of mothers generated at least one expected possible self focused on material needs (making ends meet). Forty percent of the mothers generated at least one expected possible self focused on education, and $34 \%$ of mothers generated at least one expected possible self focused on caregiving. Few mothers generated expected possible selves focused on mental health.

\section{To-Be-Avoided Possible Selves}

Perhaps because admitting to negative possible selves is difficult in American society, with its focus on positive thinking and optimism about the 
Table 3

Logistic Regression Results for Effect of Context on Possible Selves

\begin{tabular}{llll}
\hline Dependent variable & Odds ratio & $S E$ & Confidence interv \\
\hline Job-focused PS & & & \\
$\quad$ Expected & $4.47^{* *}$ & 1.71 & $2.11-9.46$ \\
To-be-avoided & $1.72 \dagger$ & 0.57 & $0.90-3.28$ \\
Strategies & $3.15^{* *}$ & 1.12 & $1.57-6.32$ \\
Balance & $2.36^{*}$ & 0.84 & $1.17-4.75$
\end{tabular}

Caregiving PS

Expected

To-be-avoided

$\begin{array}{ccc}0.59, p=.11 & 0.20 & 0.31-1.13 \\ 0.46 \dagger & 0.21 & 0.19-1.10 \\ 0.60, p=.13 & 0.20 & 0.31-1.16 \\ 0.69, p=.58 & 0.46 & 0.18-2.58\end{array}$

Strategies

$0.69, p=.58$

$0.18-2.58$

Mental health PS

Expected

To-be-avoided

Strategies

Balance

Making ends meet

Expected

To-be-avoided

Strategies

Balance

Education

Expected

$0.60, p=.21$
$0.47^{*}$
$0.46^{*}$
$0.37 \dagger$

0.24

$0.27-1.32$

0.16

0.24-0.96

0.16

$0.25-0.90$

0.22

$0.12-1.18$

To-be-avoided

Strategies

$1.49, p=.21$

0.47

0.80-2.74

$1.04, p=.91$

0.33

$0.56-1.93$

$1.30, p=.42$

0.42

$0.69-2.44$

$1.37, p=.39$

0.50

$0.67-2.79$

$0.70, p=.29$

0.24

$0.36-1.35$

$1.69, p=.38$

1.01

$0.52-5.47$

$0.90, p=.78$

0.31

$0.46-1.78$

Balance

$1.02, p=.97$

0.73

$0.26-4.12$

Note. $\mathrm{PS}=$ possible selves. Independent variable is study location: $0=D H S$ welfare office; 1 = job-training program.

$\dagger p<.10 .{ }^{*} p<.05 . * * p<.001$. 
future, $19 \%$ of mothers did not generate any to-be-avoided possible selves. To-be-avoided possible selves that were generated focused on failing to make ends meet (44\%); job-focused concerns (36\%); and mental health concerns, such as being stressed, depressed, or failing to be a good role model $(28 \%)$, and failing at one's caregiving demands $(17 \%)$.

\section{Strategies to Attain Possible Selves}

Strategies are the means by which women intend to attain or avoid their relevant possible selves. The majority of respondents generated at least one strategy related to their expected or to-be-avoided possible selves. Strategies for job attainment include general objectives, such as "looking for a job" or "going on interviews and filling out applications"; as well as more specific strategies, such as "every day I go to at least one place and fill out an application, even if I have already applied" or "looking for employment, even though I already have a job."

\section{Balanced Pairs of Possible Selves}

Overall, balance in possible selves - that is, generating both expected and to-be-avoided possible selves in the same domain-is less frequent. About one quarter of women generated balanced pairs of expected and to-beavoided possible selves focused on jobs (29\%) and on making ends meet $(23 \%)$. Although fewer of the mothers had balanced caregiving possible selves $(7 \%)$, they often reflected the challenges inherent in managing work and family; for example, expecting to be the "mom of a second child" paired with "family conflict." Some balanced caregiving possible selves reveal a desire to spend more time with children (e.g., expecting to be a "homemaker" and wanting to avoid "leaving my children," or expecting to "spend more time at home" and wanting to avoid "kids not happy"), as well as fears for children's well-being (expect to be a "better parent to my kids" and wanting to avoid "my daughter being in trouble").

\section{Descriptive Analyses}

Content of possible selves, strategies of possible selves, and balance in possible selves variables were not significantly correlated with demographic and work-family variables, with a few exceptions. Older women were less likely to generate expected possible selves focused on education $(r=-.23$, $p<.05$ ); and age was negatively correlated with having young children at 
home $(r=-.53, p<.05)$. Self-efficacy managing work-family was positively associated with being African American $(r=.22, p<.05)$, but negatively associated with being European American $(r=-.22, p<.05)$. Having more children living at home was positively correlated with generating at least one pair of balanced possible selves focused on material needs $(r=.22, p<.05)$.

Sampling site (welfare office vs. job training) was not associated with significant differences in maternal age, education, number of children, presence of young children, or work status, but it was associated with race and response to work-family variables (Table 1 ). Specifically, respondents at the welfare office site were more likely to be European American and less likely to be African American. Those at the welfare office were more likely than those in job-training programs to report higher levels of work-family conflict and low efficacy in managing work-family conflict, even though they did not have significantly more children at home or work significantly more hours per week than those in job-training programs.

Given that there were race differences by site, we explored the possibility that race (African American vs. European American) was a significant predictor of content of possible self variables (using logistic regression) and work-family variables (using ordinary least squares regression). All regression equations controlled for sample site and all other assessed demographic variables (i.e., age, education, number of children at home, presence of young children at home, whether respondent was currently working, hours worked per week), and excluded the 14 women who reported racial-ethnic backgrounds other than European American or African American. Only one of the possible self variables was significantly associated with race.

Compared with European American women, African American women were less likely to generate to-be-avoided possible selves focused on material need (odds ratio $=.33, p<.001$ ); African American women also reported significantly lower levels of work-family conflict, $F(9,239)=1.61, p<.05$; and significantly higher levels of efficacy managing work-family conflict, $F(9$, $241)=2.24, p<.01$. Even though these analyses do not suggest that demographic variables, work-family conflict, or efficacy at managing work-family variables had a strong impact on content of possible selves variables, we include all of these variables as controls to provide a conservative test of immediate context effects.

\section{Effect of Immediate Context on Possible Selves}

\section{Job-Focused Possible Selves}

Relative to mothers sampled at welfare offices, the possible selves of mothers in job-training programs were more likely to focus on jobs. They 
were nearly 5 times more likely to have at least one expected job-focused possible self (odds ratio $=4.47, p<.001$ ), marginally more likely to have at least one to-be-avoided job possible self (odds ratio $=1.72, p<.10$ ), over 3 times as likely to have at least one strategy related to their jobs-focused possible selves (odds ratio $=3.15, p<.001$ ), and over twice as likely to have at least one pair of balanced expected and to-be-avoided possible selves focused on jobs (odds ratio $=2.36, p<.05$ ).

\section{Caregiving Possible Selves}

Effects of context on caregiving possible selves were less clear-cut. At trend level, relative to mothers sampled at welfare offices, mothers in jobtraining programs were about half as likely to have at least one to-be-avoided possible self focused on caregiving (odds ratio $=.46, p<.10$ ). However, mothers in the two contexts did not differ in either likelihood of having at least one expected possible self focused on caregiving or in likelihood of having strategies or balanced possible selves focused on caregiving.

\section{Mental Health Possible Selves}

Similarly, with regard to mental-health-focused possible selves, relative to mothers sampled at welfare offices, mothers in job-training programs were less likely to have at least one to-be-avoided possible self focused on mental health problems (odds ratio $=.47, p<.05$ ), and less likely to have at least one strategy to work on a mental health possible self (odds ratio $=.46, p<.05$ ). At trend level, they were also less likely to have balance in mental health possible selves (odds ratio $=.37, p<.10$ ). However, mothers in the two contexts did not differ in either likelihood of having at least one expected possible self focused on mental health, a possible self that was uncommon in the first place.

\section{Making Ends Meet and Education-Focused Possible Selves}

Likelihood of having possible selves or strategies focused on either material needs or education did not differ by context.

\section{Discussion}

Prior research focused on middle-class adults and middle- and lowincome adolescents has suggested that possible selves are concentrated in 
domains relevant to life tasks and that having strategies and balanced possible selves improves the likelihood of successful self-regulation toward goal attainment. However, research to date has neither examined content of possible selves among low-income adults nor explored potential effects of chronic (e.g., race, education) or immediate context effects (e.g., enrolling in job training). As a step toward addressing this gap, we asked low-income mothers connected to the welfare system to describe their possible selves in the coming year.

Jobs, caring for children, and making ends meet were pervasive themes in mothers' possible selves. In many ways, responses were consistent with previous research demonstrating that possible selves are frequently articulated in ways that reflect developmentally appropriate life tasks (Frazier et al., 2000; Hooker et al., 1996; Hooker \& Kaus, 1994; Oyserman \& Markus, 1990; Oyserman et al., 2002; Strauss \& Goldberg, 1999). Given that the majority of the respondents were parenting young children, it makes sense that concerns directly related to parenting were salient.

Furthermore, for the low-income mothers in our sample, breadwinning is defined broadly. Parenting possible selves were also articulated through breadwinning, with about $8 \%$ of the making ends meet possible selves directly referencing the need to provide for one's children; for example, having a better home to raise one's children, or the goal of independently supporting one's children. Furthermore, $19 \%$ of the women who had at least one making ends meet possible self also had at least one caregiving possible self, pointing to the interface of these two domains, even as they remain distinct from one another.

While we did not find evidence that race or other demographic factors significantly predicted content of mothers' possible selves, we documented that race was a significant predictor of work-family conflict and self-efficacy at managing work and family. Although we can only speculate as to why African American women in this study had lower levels of work-family conflict and generally felt better able to handle work and family demands than did their European American counterparts, it may be that African American women living in urban environments have more social support available to handle multiple demands, as well as greater availability of employment options (Monroe \& Tiller, 2001). Again, although speculative, because we did not ask about marital status, another explanation may relate to family structure differences. Past research has demonstrated that in the United States, African Americans are less likely to marry than are Whites (Smock, 2000). With more experience as heads of households, urban African American women may not view work and family as conflicting demands in quite the same way as do their European American counterparts.

However, although race or other demographic variables did not strongly influence content of possible selves, we find that the immediately social 
context of being in a job-training program does influence the likelihood of having possible selves in the job, caregiving, and mental-health domains. Job-focused possible selves were prominent for all respondents, and they were particularly salient for mothers currently in welfare-to-work job training programs. These mothers had more positive (expected) and marginally more negative (to-be-avoided) possible selves focused on getting and keeping employment, and they were more likely to have strategies to work on these possible selves and to have balanced pairs of expected and to-be-avoided job-focused possible selves. This is consistent with previous research examining the academic attainment of adolescents, and points to a convergent interpretation. To the extent that the low-income women in this study lived in high-poverty contexts that restricted the set of employment-focused possible selves available either via models provided by close others or through personal past experience (Oyserman \& Fryberg, 2006), these mothers will have had few opportunities to "try out" employment-related possible selves and strategies. Participation in job-training programs may provide women with opportunities to elaborate on their job-focused possible selves.

Although the current study did not seek to evaluate the content of the job-training programs in which these mothers were participating, other research points to effective strategies for job-training programs. One rigorously tested, effective job-training program has been used with both middleclass and welfare-to-work samples (Lee \& Vinokur, 2007; Vinokur \& Schul, 1997). The program evaluators argue that a critical component in promoting intervention effectiveness is that participants have the opportunity to voice positive expectations and anticipate potential setbacks to achieving those goals. Focusing on the possible selves that one seeks to avoid is a way for participants to develop concrete strategies that facilitate perseverance in the face of obstacles, thus promoting goal attainment. While this program did not explicitly assess possible selves constructs (Vinokur \& Schul, 1997), participants have better employment outcomes when they are guided in the process of articulating potential setbacks, as well as positive expectations about job seeking, and then develop a plan to address those potential setbacks (Vinokur \& Schul, 1997; Vinokur, Schul, Vuori, \& Price, 2000).

In this study, we found evidence that women are able to articulate both positive and to-be-avoided possible selves related to jobs. When controlling for other factors, women currently participating in job-training programs were better able to voice a range of possible selves than mothers who were not actively involved in job training. This result is promising, given the important motivational and self-regulatory effects of well-elaborated possible selves (Markus \& Nurius, 1986; Oyserman et al., 2004; Oyserman \& Markus, 1990; Vinokur \& Schul, 1997), as well as the research cited previously. 
These results suggest that given the proper opportunities, mothers are able to mobilize self-regulatory resources that are focused on breadwinning. Considering that many low-income mothers need to focus on employment in the current social policy climate, job-training programs are likely to be helpful when they promote elaboration of expected job-related possible selves and strategies to attain those possible selves. Furthermore, women may benefit from articulating to-be-avoided possible selves - as well as balanced pairs of these possible selves - focused on breadwinning, especially when these concerns are elaborated in reference to job seeking and dealing with work-family issues.

Mothers in the job-training programs also had fewer to-be-avoided possible selves related to caregiving, perhaps because their focus on employment made it easier for them to imagine meeting their children's material needs. Consistent with other research finding that mothers conceptualize caregiving and breadwinning as somewhat overlapping obligations that both relate to being a good mother (Edin \& Kefelas, 2005; Hays, 2003), some material possible selves explicitly focus on family needs, and others may be assumed to be relevant to family preservation (e.g., keeping up with the rent). More broadly, reading the content of mothers' possible selves suggests that parenting permeates all their possible selves such that possible selves focused on jobs and making ends meet can be seen as a way to meet the responsibilities associated with caregiving as a single parent with few resources.

For the most part, in this study we did not find that focusing on employment comes at the cost of possible selves relating to caregiving. Related to this, on balance, research to date has not demonstrated negative consequences for children when mothers transition from welfare to work (ChaseLansdale et al., 2003). At least one study has linked employment to higher levels of self efficacy among poor single mothers (Jackson \& Scheines, 2005). Perhaps the intersection of employment as a way to meet caregiving responsibilities is a factor that promotes the well-being of poor women and their children.

Possible selves focused on making ends meet were equally salient for women in both the welfare and job-training contexts. This is not surprising, given that even low-income mothers who obtain employment are likely to obtain jobs with limited earnings potential that do little to alleviate common material concerns, such as those voiced in the "making ends meet" possible selves of the mothers in this sample. Furthermore, avoiding welfare reliance was a commonly mentioned to-be-avoided possible self. Consistent with past research showing that even women currently receiving welfare are ambivalent about such assistance (Hays, 2003; London, Scott, Edin, \& Hunter, 2004; Monroe \& Tiller, 2001), failing to make ends meet and being forced to receive 
aid, being on government assistance, and Work First programs are futures that women clearly wish to avoid.

How else do women see themselves getting ahead in the future? While respondents generated relatively fewer possible selves focused on education, as compared to jobs and making ends meet, it is noteworthy that so many respondents indicated that education was a relevant expected possible self. This suggests that many of the adult mothers in our study hoped for more education, but the immediate salience of employment and the need for making ends meet may have pushed education back to a more distant hopedfor self. This is likely to be especially true in a context in which welfare-reform policies focus explicitly on the need to obtain employment (rather than education and training) immediately, and in which women are provided with few resources or incentives to obtain education and training (Lee \& Oyserman, 2007). While narrowing one's focus to finding employment may be effective at promoting employment outcomes in the short term, a potential long-term ramification is that women's ability to obtain more rewarding and better-paying employment is stymied because of a lack of proper education and training.

The need to focus one's energy primarily on breadwinning may also come at the cost of focus on one's personal well-being (as operationalized by mental health possible selves and strategies). While mothers in job-training programs had fewer to-be-avoided possible selves focused on mental health concerns, they were also less likely to have strategies to attain (or to avoid negative) mental-health-related possible selves.

While many mothers expected to attain job success and to provide a better lifestyle for their family, they were also familiar with the obstacles, including mental health problems, homelessness, and lack of employment opportunities, potentially hindering attainment of possible selves. To-be-avoided possible selves described the kinds of challenges known to act as barriers to work (Danziger et al., 2000) and poignantly evoked mothers' struggles to provide basic necessities, concerns about caregiving and lack of time with children, and worries about their own mental health.

Similar to other researchers studying possible selves (Frazier \& Hooker, 2006), we found that expected and to-be-avoided possible selves diverge in important ways. Although few mothers had positive expected mental health possible selves, mental health was commonly mentioned as a to-be-avoided possible self. These results suggest that mothers do not easily imagine a pathway leading to improvement in this area, providing additional evidence suggesting that many may benefit from intervention to address mental health concerns that might get in the way of attaining desired possible selves (Lee, 2005; Lee \& Vinokur, 2007). 
Though limited by the study's cross-sectional nature, the results suggest that low-income mothers are thinking a great deal about themselves as job holders, and are likely to have at least one strategy to work toward that goal. The content of their possible selves suggests that the well-being of their children is also central, even within the context of work goals. While narrow focus on jobs may reduce focus on to-be-avoided caregiving possible selves, a focus on job may come at the cost of thinking about other goals. Clearly, this population is deserving of further study to increase understanding of how job-training interventions can successfully cue possible selves and strategies that help mothers meet their breadwinning obligations in ways that still allow them to promote their well-being and that of their children.

\section{References}

Blank, R. (2002). Evaluating welfare reform in the United States. Journal of Economic Literature, 40, 1105-1166.

Bohen, H. C., \& Viveros-Long, A. (1981). Balancing jobs and family life: Do flexible work schedules help? Philadelphia: Temple University Press.

Chase-Lansdale, P. L., Moffitt, R. A., Lohman, B. J., Cherlin, A. J., Coley, R. L., Pittman, L. D., et al. (2003). Mothers' transitions from welfare to work and the well-being of preschoolers and adolescents. Science, 7, $1548-1552$.

Cross, S. E., \& Markus, H. R. (1991). Possible selves across the life span. Human Development, 34, 230-255.

Cross, S. E., \& Markus, H. R. (1994). Self-schemas, possible selves, and competent performance. Journal of Educational Psychology, 86, 423438.

Danziger, S. K., Ananat, E. O., \& Browning, K. G. (2004). Childcare subsidies and the transition from welfare to work. Family Relations, 53, 219228.

Danziger, S. K., Corcoran, M., Danziger, S., Heflin, C., Kalil, A., Levine, J., et al. (2000). Barriers to employment of welfare recipients. In R. Cherry \& W. M. Rodgers, III (Eds.), Prosperity for all? The economic boom and African Americans (pp. 245-278). New York: Russell Sage Foundation.

Danziger, S., \& Lin, A. C. (2000). Coping with poverty: The social contexts of neighborhood, work, and family in the African-American community. Ann Arbor, MI: University of Michigan Press.

DeParle, J. (2004). American dream: Three women, ten kids, and a nation's drive to end welfare. New York: Viking. 
Edin, K., \& Kefelas, M. (2005). Promises I can keep: Why poor women put motherhood before marriage. Berkeley, CA: University of California Press.

Frazier, L. D., \& Hooker, K. (2006). Possible selves in adult development. In C. Dunkel \& J. Kerpelman (Eds.), Possible selves: Theory, research, and applications (pp. 41-59). Huntington, NY: Nova Science Publishers.

Frazier, L. D., Hooker, K., Johnson, P. M., \& Kaus, C. R. (2000). Continuity and change in possible selves in later life: A 5-year longitudinal study. Basic and Applied Social Psychology, 22, 237-243.

Haskins, R., \& Offner, P. (2003, May). Achieving compromise on welfare reform reauthorization (Brookings Institution Policy Brief: Welfare Reform and Beyond \#25). Washington, DC: Brookings Institution.

Hays, S. (2003). Flat broke with children: Women in the age of welfare reform. Oxford, UK: Oxford University Press.

Hooker, K., Fiese, B. H., Jenkins, L., Morfei, M. Z., \& Schwagler, J. (1996). Possible selves among parents of infants and preschoolers. Developmental Psychology, 32, 542-550.

Hooker, K., \& Kaus, C. R. (1994). Health-related possible selves in young and middle adulthood. Psychology and Aging, 9, 126-133.

Jackson, A. P. (1997). Effects of concerns about child care among single, employed Black mothers with preschool children. American Journal of Community Psychology, 25, 657-673.

Jackson, A. P., \& Scheines, R. (2005). Single mothers' self-efficacy, parenting in the home environment, and children's development in a two-wave study. Social Work Research, 29, 7-20.

Lee, S. J. (2005). Facilitating the welfare-to-work transition for women with a mental health work barrier. Journal of Human Behavior in the Social Environment, 12, 127-143.

Lee, S. J., \& Oyserman, D. (2007). Reaching for the future: The educationfocused possible selves of low-income mothers. In M. Rossiter (Ed.), Possible selves and adult learning: Perspectives and potential (pp. 39-49). San Francisco: Jossey-Bass.

Lee, S. J., \& Vinokur, A. D. (2007). Work barriers in the context of pathways to the employment of welfare-to-work clients. American Journal of Community Psychology, 40, 301-312.

London, A. S., Scott, E. K., Edin, K., \& Hunter, V. (2004). Welfare reform, work-family tradeoffs, and child well-being. Family Relations, 53, 148158.

Markus, H. R., \& Nurius, P. (1986). Possible selves. American Psychologist, 41, 954-969.

Monroe, P. A., \& Tiller, V. V. (2001). Commitment to work among welfarereliant women. Journal of Marriage and Family, 63, 816-828. 
Morfei, M. Z., Hooker, K., Fiese, B. H., \& Cordeiro, A. M. (2001). Continuity and change in parenting possible selves: A longitudinal follow-up. Basic and Applied Social Psychology, 23, 217-223.

Morris, J. E., \& Coley, R. L. (2004). Maternal, family, and work correlates of role strain in low-income mothers. Journal of Family Psychology, 18, $424-432$.

Oyserman, D., Bybee, D., \& Terry, K. (2006). Possible selves and academic outcomes: How and when possible selves impel action. Journal of Personality and Social Psychology, 91, 188-204.

Oyserman, D., Bybee, D., Terry, K., \& Hart-Johnson, T. (2004). Possible selves as roadmaps. Journal of Research in Personality, 38, 130149.

Oyserman, D., \& Fryberg, S. (2006). The possible selves of diverse adolescents: Content and function across gender, race, and national origin. In C. Dunkel \& J. Kerpelman (Eds.), Possible selves: Theory, research, and applications (pp. 17-39). Huntington, NY: Nova Science Publishers.

Oyserman, D., Johnson, E., \& James, L. (2009). Context effects on young teens' possible selves. Unpublished manuscript, University of MichiganAnn Arbor.

Oyserman, D., \& Markus, H. (1990). Possible selves in balance: Implications for delinquency. Journal of Social Issues, 46, 141-157.

Oyserman, D., Terry, K., \& Bybee, D. (2002). A possible selves intervention to enhance school involvement. Journal of Adolescence, 25, 313326.

Roy, K. M., Tubbs, C. Y., \& Burton, L. M. (2004). Don't have no time: Daily rhythms and the organization of time for low-income families. Family Relations, 53, 168-178.

Scott, E. K., Edin, K., London, A. S., \& Mazelis, J. M. (2001). My children come first: Welfare-reliant women's post TANF views of work-family trade-offs and marriage. In G. J. Duncan \& P. L. Chase-Lansdale (Eds.), For better and for worse: Welfare reform and the well-being of children and families (pp. 132-153). New York: Russell Sage Foundation.

Shipler, D. K. (2004). The working poor. New York: Alfred A. Knopf.

Smock, P. (2000). Cohabitation in the United States: An appraisal of research themes, findings, and implications. Annual Review of Sociology, $26,1-20$.

Strauss, R., \& Goldberg, W. A. (1999). Self and possible selves during the transition to fatherhood. Journal of Family Psychology, 13, 244 260.

Vinokur, A. D., \& Schul, Y. (1997). Mastery and inoculation against setbacks as active ingredients in the JOBS intervention for the unemployed. Journal of Consulting and Clinical Psychology, 65, 867-877. 
Vinokur, A. D., Schul, Y., Vuori, J., \& Price, R. H. (2000). Two years after a job loss: Long-term impact of the JOBS program on reemployment and mental health. Journal of Occupational Health Psychology, 5, 3247. 